Faculdade de Ciências Econômicas da UFRGS
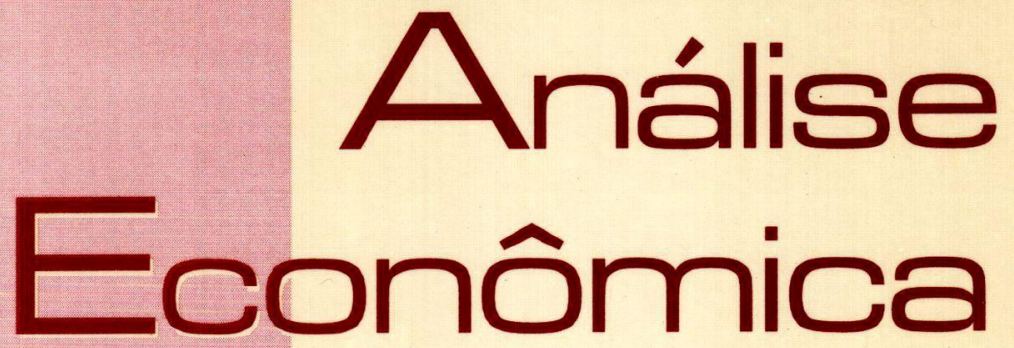

A Instabilidade Financeira dos Anos 90: Alqumas ImplicaçÕEs para as Economias Capitalistas Periféricas André Cunha e Daniela Prates

A Ampliação Recente da Participação Estrangeira no Sistema Bancário Brasileiro Maria Cristina Penido de Freitas

Infra-estrutura de Informações e Sistema Nacional de InOvação

Eduardo da Motta e Albuquerque

Custo Social dos Recursos Hídricos em Bacias Hidrográlicas Internacionais: O Caso da Bacia do Paraná Jandir Ferrera de lima e José Carrera-Fernandez

Preferência pela liọuidez e Escollha de Porrtólio

José Luis Oreiro

Eficiência, Objetivo e Coordenaçĩo da Política Macroeconômica no Período: 1974 - 1979

JoÃo Sicsú

Macroeconomia Moderna: Keynes e a ECONOMIA CONTEMPORÂNEA - RESENha

Simone Silva de Deos
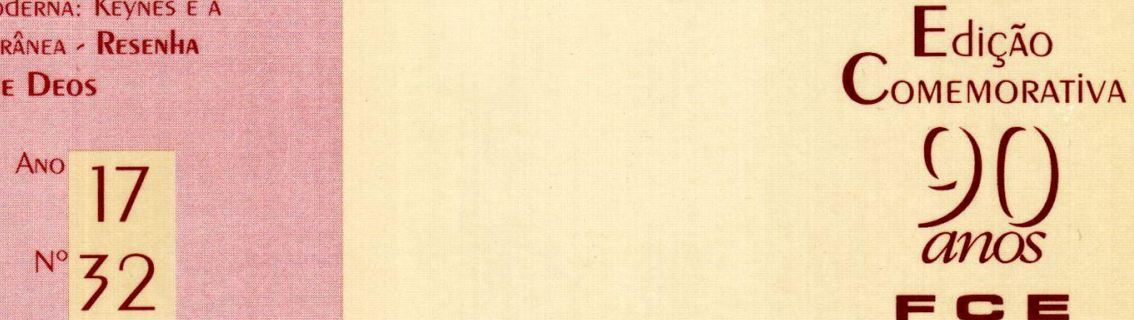

Setembro, 1999 
Universidade Federal do Rio Grande do Sul

Reitora: Proft. Wrana Maria Panizzi

Faculdade de Ciências Econômicas

Diretora: Prof ${ }^{a}$. Otilia Beatriz Kroeff Carrion

Centro de Estudos e Pesquisas Econômicas

Diretor: Prof. Fernando Ferrari Filho

Departamento de Ciencias Econômicas

Chefe: Prof Luiz Alberto Oliveira Ribeiro de Miranda

Curso de Pós-Graduação em Economia

Coordenador: Prof. Marcelo Savino Portugal

Curso de Pós-Graduaçāo em Economia Rural

Coordenador: Prof. Carlos Guilherme A. Mielitz Netto

Conselho edtrorial

Achyles B. Costa, Aray M. Feldens, Carlos A. Crusius, Carlos G. A. Mielitz Netto, Eduardo A. Maldonado Filho, Eduardo P. Ribeiro, Eugênio Lagemann, Fernando Ferrari Filho, Gentil Corazza, Marcelo S. Portugal, Nali J. Souza, Otilia B. K. Carrion, Paulo A. Spohr, Paulo D. Waquil, Pedro C. D. Fonseca, Roberto C. Moraes, Ronald Otto Hillbrecht, Stefano Florissi, Eleutério F. S. Prado (USP), Fernando H. Barbosa (FGV/RJ), Gustavo Franco (PUC/RJ), João R Sanson (UFSC), Joaquim P. Andrade (UnB), Juan H. Moldau (USP), Paul Davidson (Univ. of Tennessee), Werner Baer (Univ. of Illinois).

Comissão EDITORLAL

Eduardo Augusto Maldonado Filho, Fernando Ferrari Filho, Gentil Corazza, Marcelo Savino Portugal, Paulo Dabdab Waquil; Roberto Camps Moraes.

EDrTor: Gentil Corazza

Edrror Adjunto: Pedro Silveira Bandeira

SeCretaria: Laize Espindula.

REVISÃo DE TEXTos: Vanete Ricacheski.

Fundador: Prof. Antônio Carlos Santos Rosa

Os materiais publicados na revista Análise Econômica são da exclusiva responsabilidade dos autores. É permitida a reprodução total ou parcial dos trabalhos, desde que seja citada a fonte. Aceita-se permuta com revistas congêneres. Aceitam-se, também, livros para divulgação, elaboração de resenhas e recensões. Toda correspondência, material para publicação (vide normas na terceira capa), assinaturas e permutas devem ser dirigidos ao seguinte destinatário:

Prof, Gentul Corazza

Revista Análise Econômica - Av. João Pessoa, 52 CEP 90040-000 PORTO ALEGRE - RS, BRASIL

Telefones: 0xx (51) 316-3348 e 316-3440 - Fax: 0xx (51) 316-3990 rae@vortex.ufrgs.br

Análise Econômica

Ano 17, n. 32, setembro, 1999 - Porto Alegre

Faculdade de Ciências Econômicas, UFRGS, 1999

Periodicidade semestral, março e setembro.

ISSN 0102-9924

1. Teoria Econômica - Desenvolvimento Regional -

Economia Agrícola - Pesquisa Teórica e Aplicada -

Periódicos. I. Brasil.

Faculdade de Ciências Econômicas,

Universidade Federal do Rio Grande do Sul.

CDD 330.05

CDU 33 (81) (05) 


\title{
A ampliação recente da participação estrangeira no sistema bancário brasileiro*
}

\author{
Maria Cristina Penido de Freitas **
}

\begin{abstract}
Sinopse: Esse artigo analisa a expansão recente do capital estrangeiro no sistema financeiro brasileiro. Nesse sentido são examinados os determinantes externos e internos desse movimento, bem como as modalidades dessa expansão e o perfil das instituições recém-chegadas e suas implicações em termos das modificações das estratégias de concorrência e da reestruturação bancária privada. Finalmente, são levantadas algumas questões relativas às tendências e às perspectivas do sistema financeiro nacional.
\end{abstract}

Palavras-chave: abertura financeira, bancos estrangeiros, concorrência bancária.

\begin{abstract}
This paper discusses recent expansion of foreign banking institutions in the Brazilian financial system. The main issues examined are: the external and domestic determinants of such expansion; the means by which foreign banks are expanding their presence (acquisitions or creation of new institutions); the characteristics of the newcomers; and the competitive strategies and restructuring programs of the Brazilian private banks. The paper's conclusions deal with trends and perspectives for the Brazilian financial system.
\end{abstract}

Key Words: financial openness, foreign banks, banking competition.

\section{Introdução}

A promulgação da nova Constituição de 1988 tornou a entrada de capital estrangeiro virtualmente proibida, dado que remeteu a regulamentação do aumento da participação de investidores estrangeiros no siștema financeiro brasileiro à lei complementar, ainda não aprovada. ${ }^{1}$ Contudo, o Artigo 52 do Ato das Disposições Constitucionais Transitórias deixou em aberto a possibilidade de acesso das instituições financeiras estrangeiras ao mercado doméstico, ao prever autorizações resultantes de acordos internacionais, da aplicação do princípio de reciprocidade e dos casos que o governo julgue de "interesse nacional".2

\footnotetext{
" Este artigo é uma versão resumida e atualizada do terceiro capítulo do Relatório de Pesquisa "Abertura externa e sistema financeiro", concluído em maio de 1998 e realizado no âmbito de um convênio entre o IPEA (Brasília) e a Fundap, sob a coordenação da autora. A autora agradece os comentários e sugestões de Daniela Prates, Marcos Antônio Macedo Cintra e Carlos Eduardo Carvalho, responsabilizando-se pelas opiniôes aqui emitidas e pelos erros e omissões remanescentes.

* Doutora em Economia pela Universidade de Paris XIII e pesquisadora sênior da Área de Política Económica e Estudos Financeiros da Fundap/DIESP (E-Mail: cpenido@fundap.sp.gov.br).

Não existem restrições à transferência de participações existentes de uma instituição estrangeira para outra.

${ }^{2}$ Os preceitos desse mesmo artigo também se aplicam à abertura de novas agências de instituições bancárias estrangeiras e sob controle estrangeiro, conforme estabelece a Resolução CMN nº 1.535 de 30-11-1988.
} 
Aproveitando tal prerrogativa, em agosto de 1995, pela Exposição de Motivos $\mathbf{n}^{\circ} 311$ encaminhada pelo Ministro da Fazenda ao Presidente da República, e aprovada por este, o Governo brasileiro estabeleceu que é do interesse do País a entrada e/ou o aumento da participação de instituições estrangeiras no sistema financeiro. Tal decisão foi tomada no contexto de fragilidade crescente do sistema bancário nacional, que sofria as conseqüências de uma brutal contração de liquidez associada à implementação de políticas restritivas em resposta aos impactos da crise mexicana. ${ }^{3}$ Igualmente, a abertura do sistema financeiro brasileiro ao capital estrangeiro veio atender aos interesses de várias instituições financeiras internacionais e, ao menos parcialmente, às exigências internacionais, expressas em diferentes fóruns, tais como Organização Mundial do Comércio (OMC), Mercado Comum do Sul (Mercosul) e Área de Livre Comércio das Américas (ALCA).

Ainda no intuito de favorecer a entrada de capitais externos no sistema financeiro nacional, em 16 de novembro de 1995, o Conselho Monetário Nacional (CMN) eliminou, através da Resolução $\mathrm{n}^{\circ} 2.212$, a exigência de que o capital mínimo de um banco estrangeiro fosse o dobro daquele exigido para um banco nacional. Esse requisito havia sido fixado, quando da adesão brasileira ao Acordo da Basiléia, ocasião em que novos valores mínimos de capital para os bancos foram definidos mediante a Resolução CMN no 2.099 de 17-08-1994.

$\mathrm{Na}$ sequiência dessa breve recuperação da evolução recente do tratamento legal conferido ao capital estrangeiro no sistema financeiro nacional, serão analisados, na primeira seção, o contexto internacional e os determinantes externos da ampliação recente da presença bancária estrangeira no Brasil. Em seguida, na segunda seção, serão examinados os determinantes internos desse processo. As modalidades dessa expansão e o perfil das instituições recém-chegadas serão objeto da terceira seção. Na quarta seção, será realizada uma avaliação do impacto da maior presença dos bancos estrangeiros tanto no que se refere às alterações nas participações relativas desse segmento nos resultados do sistema bancário nacional, como suas implicações em termos das modificações das estratégias de concorrência e da reestruturação bancária privada. Finalmente, na quinta seção, à guisa de conclusão, serão levantadas algumas questões relativas às tendências e às perspectivas do sistema financeiro nacional.

\section{Os determinantes externos da ampliação da presença estrangeira}

A análise do movimento recente de ampliação da presença de instituições estrangeiras no sistema bancário brasileiro exige uma referência, ainda

${ }^{3}$ Sobre a fragilidade do sistema bancário brasileiro após a implantação do Plano Real, ver Freitas (1997a) 
que sucinta, às transformações financeiras que vêm ocorrendo desde a década passada nos países centrais. Fenômenos, tais como a desregulamentação e liberalização financeira, a proliferação de novos instrumentos e produtos e o surgimento de novos atores nos mercados de capitais associado ao processo de institucionalização da poupança financeira, revolucionaram o mundo das finanças em âmbito mundial e também nacional. Em particular, alteraram-se, de forma considerável, o espaço de valorização do capital e as condições de atuação das instituições bancárias, agentes ativos e reativos desse processo de mutações financeiras. ${ }^{4}$

Os bancos tiveram de superar inúmeras dificuldades no processo de transição para sistemas financeiros mais liberalizados. Com efeito, em certos países, essas instituições se defrontaram com a emergência de novos concorrentes em atividades que lhes eram exclusivas, enquanto permaneciam submetidas a restrições que não se aplicavam aos novos rivais. Nos diferentes contextos institucionais nacionais, a concorrência com as instituições financeiras não-bancárias e, mesmo, entre os bancos e organizações empresariais nãofinanceiras, aparece sob diversas formas. Em países em que existia a segmentação institucional entre atividade bancária comercial e de investimento, novos atores penetraram no mercado de crédito comercial, tais como: os bancos de investimentos, as companhias de crédito hipotecário, as seguradoras e as companhias de "crédito cativo", empresas financeiras não-bancárias vinculadas aos grandes grupos industriais (por exemplo, nos Estados Unidos, a General Motors Acceptance Corporation e a General Eletric Capital Service).

Os bancos estão também em concorrência direta com os investidores institucionais pela captação da poupança financeira líquida das empresas e das famílias. Por essa razão, em vários países, os bancos têm se defrontado com alterações profundas das suas fontes de funding. Os depósitos tradicionais perderam importância frente aos instrumentos do mercado monetário, como os fundos de investimento, em que os valores das quotas adquiridas pelos aplicadores são comparados diariamente, aumentando o custo da captação bancária.

Igualmente, na esfera institucional dos sistemas de pagamentos, os bancos têm enfrentado competição das empresas não-financeiras, que oferecem software para cartões de crédito e terminais eletrônicos de serviços financeiros, ou ainda desenvolvem cartões de crédito pré-pagos. Esses novos instrumentos "semibancários" incluem serviços de pagamentos, seguros e créditos, oferecidos e administrados por grandes redes comerciais varejistas, como a Sears nos Estados Unidos, e os grandes magazines

\footnotetext{
${ }^{4}$ Sobre as transformações financeiras nos países centrais, ver, entre outros, OECD (1992), Blommestein (1995), Freitas (1997b) e, em particular para o caso americano, Cintra (1997).
} 
(department stores) no Japão, França e Reino Unido (Freitas, 1997b).

Nesse movimento de adaptação às novas condições de concorrência, inúmeras instituições faliram ou foram absorvidas por seus concorrentes. Algumas delas adotaram estratégias de diversificação de atividades que as levaram a assumir riscos elevados. Outras não conseguiram defender seus espaços de valorização frente aos novos rivais que possuíam vantagens competitivas mais importantes.

Essas mudanças verificadas no ambiente concorrencial dos bancos desencadearam um processo de concentração e reestruturação dos sistemas bancários, o qual se manifesta, na maior parte dos países, em ondas sucessivas de fusões e aquisições. Esse movimento -- que se realimenta na própria busca de ampliação da base de clientes e de negócios inerente à dinâmica concorrencial - aponta para uma contínua tendência de diminuição do número de instituições bancárias e de aumento da concentração.

Além da concentração e centralização, mediante fusões e aquisições, em âmbito doméstico, a dinâmica concorrencial do sistema financeiro vem estimulando, igualmente, a diversificação geográfica e a atuação global nos diferentes mercados e segmentos. Por exemplo, na Europa, onde os mercados bancários domésticos estão saturados, é grande a possibilidade de pequenos bancos serem absorvidos pelos maiores, devido às condições macroeconômicas domésticas, de baixo crescimento e baixas taxas de inflação e de juros. Nesse contexto, as estimativas indicam que os bancos terão dificuldade para ampliar seus ativos e reduzir seus custos, o que se traduziria em margens menores e, por conseqüência, menores lucros. A unificação monetária, iniciada em janeiro de 1999, deverá pressionar ainda mais as margens bancárias, sobretudo aquelas praticadas nos empréstimos a empresas, em países como Espanha, Itália e Portugal. Quando os empréstimos forem denominados na moeda européia, os tomadores desses países encontrarão banqueiros estrangeiros dispostos a oferecer crédito mais barato.

De igual modo, se a introdução do euro viabilizar a criação de um amplo mercado de capitais, capaz de rivalizar com o mercado americano em termos de volume e liquidez, as grandes empresas européias terão maiores facilidades para levantar recursos em moeda local em condições favoráveis. Mesmo as empresas menores terão a oportunidade de tentar se financiar sem recorrer aos bancos, o que pressionará ainda mais as margens bancárias.

A competição acirrada exige grandes bancos com amplos canais de distribuição. Como há limite para compressão dos custos, o caminho é ampliar a massa de clientes e o volume de negócios. Isso se traduz na estratégia de fortalecimento da posição global. A grande maioria dos bancos que atua em âmbito internacional expandiu suas atividades no exterior, após alguns anos de retração na década de 
80, motivada pela crise da dívida dos países do Terceiro Mundo. Em certa medida, esse novo esforço de internacionalização deriva das pressões concorrenciais intensas nos mercados nacionais já assinaladas. Contudo, é preciso ressaltar que esse movimento recente apresenta alguns traços distintos em relação a internacionalização bancária dos anos 60 e 70.

Naquela época, esse movimento se traduzia na implantação de entidades no estrangeiro, com o objetivo de acompanhar a internacionalização dos seus principais clientes nacionais, de viabilizar o acesso das grandes empresas públicas e privadas do país anfitrião ao mercado internacional de crédito em euromoedas e, em menor grau, de conquistar espaço no mercado bancário local (Freitas, 1989).

Embora seus mais importantes clientes no exterior continuem sendo as filiais locais das empresas-clientes do país de origem, dado o predomínio dos mercados internacionais de capitais como fonte de financiamento das grandes empresas, os bancos têm procurado, atualmente, ampliar suas atividades nos mercados de serviços financeiros dos países anfitriões, sobretudo mediante a aquisição e/ou participação acionária em instituições domésticas. Em outras palavras, as estratégias de apoio e financiamento externo e diversificação que prevaleceram no passado cederam a primazia à estratégia de diversificação das atividades no mercado local, o que exige redes de agências mais densas e maior integração com o sistema bancário doméstico. Tal estratégia tem sido viabilizada pela abolição ou flexibilização gradativa das restrições relativas à instalação de filiais e/ou sucursais, à participação estrangeira no capital de instituições nacionais e às atividades de bancos estrangeiros nos mercados domésticos, tanto nos países desenvolvidos como em diversos países em desenvolvimento.

As atividades no exterior são fontes de importantes receitas para os grandes bancos internacionais. Aqueles que possuem vastas redes de dependências externas, como o Standard Chartered, o HSBC, o Crédit Agricole e o Citibank, obtêm a maior parte de suas receitas totais no estrangeiro, como revelam os dados da Tabela 1. Nessa Tabela estão listados 30 dos 50 maiores bancos globais, classificados pela revista The Banker, de acordo com o peso dos ativos no exterior como porcentagem dos ativos totais. ${ }^{5}$ Entre esses, 22 são bancos europeus, três americanos, três canadenses e dois australianos.

Nesse quadro geral descrito acima, insere-se o movimento recente de ingresso de importantes grupos financeiros internacionais que está ocorrendo em toda a América Latina nos últimos anos. Os países de língua espanhola foram os primeiros a ser alvo de investimentos diretos das instituições financeiras estrangeiras. A estabilização das economias locais e as

\footnotetext{
${ }^{5} \mathrm{Na}$ elaboração do ranking dos cinquenta maiores bancos globais, a revista The Banker considerou apenas aquelas instituições, cujos ativos no exterior superavam os $20 \%$ dos ativos totais.
} 
Tabela 1: Os 30 Maiores Bancos Globais por Ativos no Exterior como \% dos Ativos Totais

\begin{tabular}{|c|c|c|c|c|c|c|c|}
\hline $\begin{array}{l}\text { Ran } \\
\text { king } \\
\text { Global }\end{array}$ & $\begin{array}{l}\text { Ranking } \\
\text { Mundial } \\
\text { por } \\
\text { Capital }\end{array}$ & Instituições & $\begin{array}{l}\text { Pais de } \\
\text { Origem }\end{array}$ & $\begin{array}{l}\text { Capital } \\
\text { Tiers } \\
\text { One } \\
\text { (US\$ } \\
\text { milhōes) }\end{array}$ & $\begin{array}{l}\text { Ativo } \\
\text { Total (USS } \\
\text { milhões) }\end{array}$ & $\begin{array}{l}\text { Ativo no } \\
\text { Exterior/ } \\
\text { AtivoTota } \\
\text { I }(\%)\end{array}$ & $\begin{array}{l}\text { Receita } \\
\text { no } \\
\text { Exterior/ } \\
\text { Receita } \\
\text { Total }(\%)\end{array}$ \\
\hline 1 & 344 & $\begin{array}{l}\text { America Express } \\
\text { Bank }\end{array}$ & Est. Unidos & 830 & 12.615 & 79,98 & 91,49 \\
\hline 2 & 92 & Standard Chartered & Reino Unido & 4.189 & 78.024 & 74,00 & 84,00 \\
\hline 3 & 16 & Credit Suisse Group & Suíça & 12.984 & 473.832 & 73,00 & 45,00 \\
\hline 4 & 14 & $\begin{array}{l}\text { Union B of } \\
\text { Switzerland }\end{array}$ & Suíça & 13.570 & 396.878 & 68,40 & 39,50 \\
\hline 5 & 52 & Suiss Banking Group & Suíça & 6.371 & 301.620 & 67,20 & 38,70 \\
\hline 6 & 1 & HSBC Holding & Reino Unido & 27.392 & 473.608 & 65,00 & 52,00 \\
\hline 7 & 4 & Citicorp. & Est. Unidos & 21.211 & 310.897 & 63,00 & 70,00 \\
\hline 8 & 91 & $\begin{array}{l}\text { Bank Austria- } \\
\text { Creditanstalt }\end{array}$ & Áustria & 4.241 & 124.157 & 57,35 & 32,99 \\
\hline 9 & 8 & ABN Amro Bank & Holanda & 15.864 & 414.654 & 57,09 & 52,81 \\
\hline 10 & 38 & $\begin{array}{l}\text { Cia Financière } \\
\text { Paribas }\end{array}$ & França & 8.538 & 245.188 & 55,05 & 38,97 \\
\hline 11 & 48 & Crédit Lyonnais & França & 7131 & 250.279 & 53,80 & 42,00 \\
\hline 12 & 104 & Krediebank & Bélgica & 3588 & 112.898 & 53,10 & 30,90 \\
\hline 13 & 124 & Allied Irish Banks & Irlanda & 2.910 & 53.830 & 53,00 & 60,00 \\
\hline 14 & 21 & JP Morgan & Est. Unidos & 11.854 & 262.159 & 52,74 & 49,90 \\
\hline 15 & 6 & Deutsch Bank & Alemanha & 17.371 & 581.979 & 52,66 & 27,41 \\
\hline 16 & 51 & Bankers Trust & Est Unidos & 6.431 & 140.102 & 51,87 & 35,81 \\
\hline 17 & 44 & $\begin{array}{l}\text { National Australia } \\
\text { Bank }^{(1)}\end{array}$ & Austrália & 7.552 & 145.763 & 50,70 & 47,20 \\
\hline 18 & 45 & $\begin{array}{l}\text { Canadian Imp. B. of } \\
C^{(2)}\end{array}$ & Canadá & 7.429 & 165.165 & 49,00 & 22,00 \\
\hline 19 & 81 & $\begin{array}{l}\text { Banca Commerciale } \\
\text { Italiana }\end{array}$ & Itália & 4.717 & 115.789 & 43,60 & 44,50 \\
\hline 20 & 154 & $\begin{array}{l}\text { Canadian Imp. B of } \\
\text { C. }{ }_{(2)}\end{array}$ & Irlanda & 2.153 & 53.994 & 48,10 & 33,00 \\
\hline 21 & 19 & $\begin{array}{l}\text { National } \\
\text { Westminster. }\end{array}$ & Reino Unido & 12.324 & 306.603 & 47,39 & 31,62 \\
\hline 22 & 40 & Banco Santander & Espanha & 7.952 & 171.092 & 48,00 & 43,00 \\
\hline 23 & 54 & Bank of Montreal (2) & Canadá & 6.140 & 150.815 & 47,67 & 43,48 \\
\hline 24 & 50 & $\begin{array}{l}\text { Banco Bilbao } \\
\text { Vizcaya }\end{array}$ & Espanha & 6.800 & 139.346 & 46,60 & 51,00 \\
\hline 25 & 49 & Scotiabank $k^{(1)}$ & Canadá & 6.820 & 141.610 & 43,00 & 44,00 \\
\hline 26 & 28 & Dresdner Bank & Alemanha & 10.456 & 372.594 & 42,00 & 33,00 \\
\hline 27 & 31 & Societé Générale & França & 9.745 & 441.115 & 41,40 & $\mathrm{n} d$ \\
\hline 28 & 107 & Central Hispano & Espanha & 3454 & 77.386 & 38,40 & 13,90 \\
\hline 29 & 126 & $\begin{array}{l}\text { Banque Bruxelles } \\
\text { Lambert }\end{array}$ & Bélgica & 2.877 & 111.970 & 37,81 & n. d. \\
\hline 30 & 73 & $\begin{array}{l}\text { ANZ Banking } \\
\text { Group }^{(1)}\end{array}$ & Austrália & 5.032 & 99.770 & 37,00 & 44,00 \\
\hline
\end{tabular}

Fonte: The Banker, "Top 50 global banks", February, 1999, pp. 40-41 e The Banker, "Top 1000 World banks", July, 1998, pp.

\section{Notas:}

n.d. - informação não disponível.

(1) Posição em setembro de 1998

(2) Posição em outubro de 1998

(3) Posição em março de 1998 
perspectivas de retornos elevados devido ao predomínio de competidores locais relativamente mais fracos foram os atrativos que se aliaram à necessidade de diversificação fora de mercados domésticos já saturados. Na segunda metade dos anos 90, chegou a vez do Brasil, o mercado mais cobiçado da região, pois é fonte de receitas expressivas para os bancos estrangeiros aqui já instalados.

\section{Os determinantes internos}

As perspectivas de estabilização sustentada da economia brasileira a partir da introdução do Plano Real, em junho de 1994, aumentou o interesse de um número crescente de instituições financeiras estrangeiras, tanto da área comercial como de investimento, em atuar no País, através de associações com bancos nacionais e/ou através da instalação de agências.

A abertura do mercado de capitais, o processo de privatização e as perspectivas de negócios naárea de financiamento da infra-estrutura ampliaram as possibilidades de negóciose de lucros, sobretudono segmento bancáriode investimento. Destacam-se nesse segmento a administração de recursos de investidores institucionais estrangeiros, a estruturação de operações de privatização e project finance, o lançamentos de ações e títulos brasileiros no País e no exterior e a assessoria nos processos de reestruturação de empresas brasileiras.

$O$ potencial de crescimento do varejo e a expectativa de generalização do uso de contas bancárias, dado que a relação entre o número de conta bancária e o tamanho da população ainda é baixa no Brasil, apresentam, igualmente, forte atratividade para os bancos estrangeiros. Enquanto no Brasil há cerca de uma agência bancária para cada 4.500 pessoas $^{6}$, existe uma agência para 2.900 pessoas na Itália; uma para cada 2.000 pessoas na Alemanha e uma para 1.100 na Espanha ('The Economist, 1998: 61).

A estabilização econômica e o potencial de negócios vultosos definem condições ideais para o aumento da presença estrangeira no sistema financeiro nacional. Contudo, tal movimento não seria viabilizado se não ocorresse uma alteração decisiva no marco legal relativo ao tratamento conferido ao capital estrangeiro. Nesse sentido, a decisão presidencial em utilizar as prerrogativas previstas no Artigo 52 das Disposições Constitucionais Transitórias é elemento explicativo essencial da internacionalização recente do sistema financeiro nacional.

$\mathrm{O}$ anúncio oficial de que o governo lançaria mão desse expediente sempre que necessário, tanto para permitir a participação estrangeira na capitalização de instituições financeiras privadas nacionais e/ou no processo de privatização dos bancos oficiais, como para promover a moderni-

\footnotetext{
${ }^{6}$ Posição em dezembro de 1996, ano da última estatística disponível para a população economicamente ativa (PEA), considerada para o cálculo dessa relação. Esse número cai para 2.883 pessoas, se incluídos os postos de serviços.
} 
zação do sistema financeiro nacional, contribuiu para exacerbar o anseio das instituições financeiras estrangeiras por ingressar no mercado brasileiro. Multiplicaram-se os contatos entre bancos nacionais e estrangeiros interessados em efetuar associações, adquirir participação acionária majoritária ou integral. Esse movimento tomou tal dimensão que o Banco Central precisou relembrar aos interessados que a entrada de capital externo no setor necessita de autorização prévia da Presidência da República. ${ }^{7}$

Como há inúmeras instituições procurando ingressar no País, o Banco Central passou a exigir o pagamento de um "pedágio", a título de contribuição para a recuperação dos recursos públicos utilizados no saneamento do sistema financeiro. ${ }^{8}$ Embora não haja critérios claros e estritos, segundo informação obtida junto ao Departamento de Organização do Sistema Financeiro, o valor do "pedágio" tem sido definido em função do capital mínimo exigido para cada modalidade de instituição financeira. Até fevereiro de 1998, o Banco Central já havia recebido cerca de $\mathrm{R} \$ 122$ milhões (e aguardava recebimento de outros R $\$ 44$ milhões) em troca de 24 autorizações de entrada, aquisição e/ ou ampliação de participação acionária em instituições financeiras domésticas (Medeiros, 1998).

\section{Modalidades de expansão e perfil dos recém-chegados}

Entre outubro de 1995 e abril de 1998, 24 instituições financeiras estrangeiras foram autorizadas a se instalar no País, seja mediante a aquisição do controle acionário de entidades nacionais, inclusive daquelas que já possuíam participação estrangeira, seja mediante constituição de subsidiária e/ou sucursal bancária ou da implantação de empresa de arrendamento mercantil e/ou distribuidora de títulos e valores mobiliários. Desse total, 14 são instituições bancárias comerciais ou múltiplas - das quais nove estão entre os 100 maiores bancos do mundo por capital --, três são bancos de investimentos e as demais são instituições financeiras não-bancárias vinculadas, em sua maioria, a importantes grupos industriais.

O banco holandês Rabobank Nederlands foi a primeira instituição estrangeira a se beneficiar da política de abertura do sistema financeiro depois da edição da Exposição de Motivo n ${ }^{\circ} 311$, sendo autorizado a operar no Brasil por Decreto Presidencial de 08-08-1995. Esse é o segundo maior banco de crédito cooperativo do mundo e já se encontrava presente no Brasil, desde 1989, sob a forma de escritório de representação. Em 1995, o Banco Comerci-

\footnotetext{
${ }^{7}$ No dia 10 de setembro de 1997, o Banco Central divulgou Comunicado $\mathrm{n}^{\circ} 5796$, lembrando aos interessados que há exigência de consulta prévia para aquisição de participação acionária em bancos nacionais por instituições estrangeiras.

${ }^{8}$ Não há informações disponíveis sobre a forma em que são efetuados e contabilizados esses pagamentos.
} 
al S.A., do Uruguai, foi também autorizado a constituir instituição financeira no Brasil.

Em 1996, o Presidente da República autorizou o ingresso de outras cinco instituições, entre as quais o Republic National Bank, um dos maiores bancos de Nova YorK e, na época, o $17^{\circ}$ banco americano por volume de ativos. Ao contrário dos bancos europeus, Banque Nationale de Paris e do Dresdner Group, que assumiram passivos de bancos em regime de liquidação, a título de contribuição ao saneamento do sistema financeiro nacional, aquele banco americano não teve de pagar "pedágio", pois comprou os direitos de um outro banco estrangeiro, o Banco Exterior de España.

No ano de 1997, no qual se concentrou o maior número de autorização de ingresso de instituições financeiras desde a edição da Exposição de Motivo $\mathrm{n}^{\mathbf{0}} 311$, ocorreu a entrada de 13 novas instituições estrangeiras, entre bancos comerciais, de investimento e financeiras. Desse total, sete são provenientes dos Estados Unidos, duas são britânicas, duas suíças, uma francesa e outra espanhola. A grande maioria dessas instituições teve acesso ao sistema financeiro brasileiro através da aquisição de participação acionária em instituições domésticas. Praticamente todas pagaram "pedágio" ao Banco Central. As exceções foram o Wachovia Corporation, que comprou a subsidiária brasileira do Banco Português Atlântico e o Hongkong Shangai Banking Corporation (HSBC), que adquiriu o Bamerindus com recursos do PROER 9 .

Presente em mais de 78 países e um dos maiores bancos do mundo em termos de capital, o HSBC tornou-se, pela aquisição dos ativos do Bamerindus, o maior banco estrangeiro do sistema financeiro brasileiro, tanto em volume de ativos como em extensão da rede bancária. Essa compra também merece destaque pela sua singularidade. Pela primeira vez, no Brasil, a falência de uma grande instituição doméstica foi resolvida mediante a sua venda a entidade estrangeira. Mesmo em âmbito mundial, não se tem registro de um episódio semelhante, não obstante o movimento crescente de fusões e aquisições bancárias, observado tanto nos países centrais como nos países em desenvolvimento.

Nos quatro primeiros meses de 1998, quatro novas instituições financeiras foram autorizadas a ingressar no mercado brasileiro: três através da aquisi-

\footnotetext{
${ }^{9} \mathrm{O}$ Proer, Programa de Estímulo à Reestruturação e ao Fortalecimento do Sistema Financeiro Nacional, foi instituído por meio da Medida Provisória n ${ }^{\circ} 1.179$ de 3-11-1995, como um mecanismo de financiamento da absorção de bancos em dificuldades por instituições saudáveis. Pelo Proer, os passivos e ativos recuperáveis das instituiçôes insolventes são transferidos para outras instituições, enquanto os débitos irrecuperáveis são absorvidos pelo Banco Central, que também financia a absorção pelos bancos adquirentes da parcela recuperável da carteira da instituição insolvente. Desde a sua criação até a venda do Bamerindus ao HSBC, o total de recursos liberados por esse programa atingiu R 20,8 bilhões. Para maiores detalhes sobre esse programa, ver Freitas (1997a)
} 
ção de controle acionário de banco privado nacional e uma mediante a instalação de um novo banco. Por se tratar de aquisição de instituição em dificuldades financeiras, não foi cobrado "pedágio" do português Caixa Geral de Depósitos que adquiriu o Banco Bandeirantes nem do Bilbao Viscaya que adquiriu o Excel-Econômico. O mesmo não ocorreu com a GE Capital Service, braço financeiro do grupo industrial americano General Eletric, a qual teve de pagar $\mathrm{R} \$ 11,2$ milhões ao Banco Central para adquirir a integralidade do controle do Banco Mappin e 60\% da financeira de mesmo Grupo.

Em maio de 1998, ocorreu o anúncio da aquisição de mais um banco doméstico por um grupo estrangeiro. Após meses de negociações com vários interessados e muitos desmentidos oficiais, a diretoria do Banco Garantia divulgou a aceitação da proposta de compra apresentada pelo Crédit Suisse First Boston (CSFB), banco de investimento do Grupo Crédit Suisse. O Garantia foi um dos bancos brasileiros que mais sofreu o impacto dos desdobramentos da crise dos países asiáticos no quarto trimestre de 1997.

Ao lado do ingresso de novas instituições, observa-se a expansão dos bancos estrangeiros já em atividade no sistema financeiro nacional. Entre julho de 1995 e julho de 1998, registram-se 20 operações envolvendo o aumento da presença estrangeira, sob várias formas: instalação de novas unidades de negócio, associações, aquisição e/ou ampliação da participação acionária em instituições domésticas.

Dentre as transações realizadas por instituições estrangeiras já em atividade no sistema bancário brasileiro, destacam-se as duas aquisições efetuadas pelo espanhol Santander, cuja estratégia global visa, claramente, reforçar sua presença nas principais economias latino-americanas e ampliar sua participação no segmento bancário varejista dos países em que atua. Mediante a compra do Banco Geral do Comércio e do Noroeste, essa instituição adquiriu a segunda maior rede bancária sob controle estrangeiro (365 unidades entre agências e postos) do País, ficando atrás apenas do HSBC Bamerindus (1.842 unidades) e empurrando provisoriamente para o terceiro lugar o Banco Sudameris do Brasil, que recuperou a posição de segundo maior banco estrangeiro por rede de agência ao adquirir o banco América do Sul em março de 1998. Em julho de 1998, o Banco Central autorizou a compra pelo ABN-Amro Bank de $40 \%$ do capital social do Banco Real. Por essa aquisição, o banco holandês pagou $\mathrm{R} \$ 2$ bilhões, concretizando a maior transação em termos financeiros já realizada no mercado bancário brasileiro.

Como nas autorizações de ingresso de novas instituições, a ampliação da presença estrangeira também envolveu o pagamento de "pedágio" ao Banco Central. As exceções se explicam, mais uma vez, pelas dificuldades financeiras dos bancos domésticos absorvidos pelos estrangeiros. Tais foram os casos 
da transferência, no mês de setembro de 1997, do controle acionário do Boavista para o Banco Inter-Atlântico - cujos principais acionistas são o banco português Espírito Santo, o Grupo Monteiro Aranha e o banco francês Crédit Agricole (Borges \& Luane, 1997) - e da aquisição do América do Sul pelo banco Sudameris, em março de 1998.

A ampliação da presença estrangeira no sistema financeiro brasileiro tem ocorrido também através da instalação e/ou aquisição de instituições financeiras não-bancárias. Esse é o caso do Deutsche Bank, que obteve autorização para instalar uma corretora de valores e também do Citibank e do BankBoston que decidiram constituir companhias hipotecárias. Igualmente, o Lloyds Bank adquiriu, em busca de diversificação, a financeira Losango, a qual detém a maior carteira de crédito para pessoa física do Brasil, de US $\$ 1,3$ bilhões e 12 milhões de clientes. Presente no País há mais de 135 anos e concentrando suas atividades no segmento atacadista, esse grande banco inglês conquistou, desse modo, uma grande fatia do mercado de crédito direto ao consumidor, que é um mercado muito cobiçado (Carvalho, 1997).

\section{O impacto do aumento da participação estrangeira no sistema financeiro nacional}

O Banco Central, em sua Carta-circular n. ${ }^{\circ} 2345 / 93$, classifica as instituições estrangeiras em três categorias, segundo o controle do capital: bancos estrangeiros, bancos com controle estrangeiro e banco com participação estrangeira ${ }^{10}$. Considerando as três categorias em seu conjunto, constata-se pelo exame da Tabela 2 que não houve aumento sensível no número de instituições estrangeiras presentes no mercado brasileiro entre junho de 1995 e dezembro de 1998, que de 68 passou a 76, o que se explica tanto pela existência de certo descompasso entre as alterações ocorridas e sua incorporação nas estatísticas como pelo fato da obtenção de autorização de ingresso não se traduzir imediatamente na instalação de novas instituições. Todavia, no período em foco, enquanto se reduziu o número de instituições com participação estrangeira, o número de bancos nacionais com controle estrangeiro aumentou significativamente. De igual modo, em seu conjunto a participação estrangeira em termos do número de dependências, saltou de 2,6\% em junho de 1995 para 19,47\% em dezembro de 1998, em virtude da aquisição, entre outros, do Bamerindus pelo HSBC, do Banco Noroeste pelo Santander, do Excel-Econômico pelo BBV e do Banco Real pelo ABN Amro.

\footnotetext{
${ }^{10}$ As instituições definidas como banco estrangeiro só podem atuar no Pais sob a forma de banco comercial, pois a organização bancária múltipla é privativa dos bancos constituídos sob legislação brasileira. Por essa razão, vários bancos estrangeiros já presentes no País a vários anos constituíram subsidiária brasileira de controle integral, como é o caso do Citibank, do Lloyds e do BankBoston.
} 
Tabela 2: Evolução Recente do Número de Bancos Estrangeiros por Tipo e Rede de Agência

\begin{tabular}{l|l|l|l|l}
\hline \multirow{2}{*}{ Tipo de Instituição } & \multicolumn{2}{|l|}{ jun/95 } & \multicolumn{2}{l}{ dez/98 } \\
\cline { 2 - 5 } & N. ${ }^{\circ}$ de Sede & $\begin{array}{l}\text { N. }{ }^{\circ} \text { de } \\
\text { Agência }\end{array}$ & N. ${ }^{\circ}$ de Sede & $\begin{array}{l}\text { N. }{ }^{\circ} \text { de } \\
\text { Agência }\end{array}$ \\
\hline Banco Estrangeiro ${ }^{(1)}$ & 18 & 157 & 16 & 37 \\
Controle Estrangeiro $^{(2)}$ & 20 & 410 & 42 & 2.327 \\
Participação Estrangeira $^{(3)}$ & 30 & 306 & 18 & 786 \\
Total Estrangeiros & 68 & 853 & 76 & 3.150 \\
Participação Sistema & 27,9 & 2,6 & 37,61 & 19,47 \\
Bancário Nacional (\%) & & & & \\
\hline
\end{tabular}

Fonte: Banco Central do Brasil - SISBACEN e Departamento Econômico/DIMOB

(1) São definidos como bancos estrangeiros as dependências ou filiais de bancos sediados no exterior.

(2) Os bancos privados nacionais com controle estrangeiro são aqueles cuja maioria do capital votante pertence, direta ou indiretamente, a instituições bancárias sediadas no exterior.

(3) Como bancos privados nacionais com participação estrangeira incluem-se aqueles em que de $10 \%$ a $50 \%$ do capital votante pertence, de modo direto ou indireto, a bancos sediados no exterior.

A partir da análise da evolução de algumas das principais contas dos balancetes, é possível observar alguns indícios da ampliação da participação das instituições estrangeiras no sistema bancário nacional (Tabela 3). Nota-se que a participação do segmento estrangeiro nos ativos totais do setor bancário nacional saltou de $10,4 \%$ para $24,7 \%$ entre junho de 1995 e junho de 1998 , recuando ligeiramente para $22,53 \%$ em dezembro de 1998 . A mesma tendência de expansão se observa no caso da captação de recursos externos que passou de $34,75 \%$ em dezembro de 1995 para 49,90\% em dezembro de 1998 . No que se refere às operações de crédito e dos depósitos totais, a participação estran-

Tabela 3: Evolução da Participação Estrangeira no Sistema Bancário Nacional - em \%

\begin{tabular}{llllll}
\hline Período & $\begin{array}{l}\text { Ativos } \\
\text { Totais }(\%)\end{array}$ & $\begin{array}{l}\text { Oper. de } \\
\text { Crédito (\%) }\end{array}$ & $\begin{array}{l}\text { Depósitos } \\
\text { Totais (\%) }\end{array}$ & $\begin{array}{l}\text { Patrimônio } \\
\text { Líquido } \\
(\%)\end{array}$ & $\begin{array}{l}\text { Captações } \\
\text { de } \\
\text { Recursos } \\
\text { externos } \\
(\%)\end{array}$ \\
\hline jun/95 & 10,42 & 6,47 & 7,14 & 15,02 & 34,57 \\
dez/95 & 11,90 & 7,04 & 8,98 & 18,23 & 41.07 \\
jun/96 & 14,02 & 9,31 & 6,75 & 16,41 & 44,08 \\
dez/96 & 13,55 & 10,61 & 8,66 & 16,95 & 39,23 \\
jun/97 & 17,77 & 9,45 & 13,28 & 20,01 & 37,37 \\
dez/97 & 21,08 & 9,81 & 16,34 & 25,78 & 45,34 \\
jun/98 & 24,75 & 7,12 & 17,30 & 25,48 & 48,31 \\
dez/98 & 22,53 & 20,98 & 17,10 & 26,02 & 49,90 \\
\hline Por memória & & & & & \\
Sistema Bancário & 529.169 & 148.147 & 228.695 & 45.148 & 54.219 \\
$\begin{array}{l}\text { Nacional (US\$ } \\
\text { milhões) }\end{array}$ & & & & & \\
\hline
\end{tabular}

Fonte: Banco Central do Brasil - SISBACEN e Departamento Econômico/DIMOB 
geira aumentou em 1995 e 1996, declinando nos semestres seguintes e crescendo de forma espetacular no segundo semestre de 1998, quando atingiu 20,98\% em dezembro, entre outras razões, em virtude da compra do Banco Real pelo ABN Amro e do Excel Econômico pelo Bilbao Viscaya. Quanto ao patrimônio líquido, a participação estrangeira apresentou forte avanço a partir de junho de 1997, refletindo as aquisições de importantes instituições domésticas.

O processo de adaptação e transição do sistema bancário às novas condições operacionais ainda não se completou. Há expectativas de novas fusões e de ampliação da participação dos bancos estrangeiros no mercado doméstico. A abertura do sistema financeiro brasileiro está promovendo uma ampla revisão das estratégias concorrenciais não apenas dos bancos nacionais como também dos bancos estrangeiros presentes no País. A entrada de novos concorrentes e a ampliação dos bancos estrangeiros já em atividade deverão provocar a redefinição das estratégias concorrenciais não só dos grandes bancos varejistas, mas também dos bancos que atuam no mercado de atacado realizando operações com as multinacionais e as grandes empresas nacionais exportadoras.

O mercado brasileiro de varejo deverá se transformar, nos próximos anos, em palco de disputa acirrada entre os bancos participantes, sejam eles nacionais ou estrangeiros. Nesse segmento, em que o conhecimento das peculiaridades do mercado local é muito importante, os bancos estrangeiros que dispõem de maior poderio financeiro devem forçar a modernização e a reestruturação das instituições, mas dificilmente conseguirão expulsar os bancos tradicionais, como o Bradesco, o Itaú e Unibanco. Por sua vez, esses têm procurado fortalecer suas posições, adquirindo outras instituições. O Bradesco comprou o BCN, que enfrentava dificuldades após a aquisição do Credireal, enquanto o Itaú arrematou o Banerj e o Bemge, nos respectivos leilóes de privatização. Além do Banco Nacional, o Unibanco adquiriu o Banco Dibens, especializado no financiamento, consórcio, leasing financeiro e operacional de veículos leves e pesados.

O Itaú realizou também uma associação com o Bankers Trust, adotando uma estratégia defensiva de sobrevivência em um mercado que exige capacidade de atuação global, como é o caso do segmento bancário de investimento. Para não perder espaço, o Itaú optou pela parceria, que é vantajosa para ambas as instituições, pois alia o conhecimento local da instituição brasileira à experiência do banco americano no mercado internacional de capitais.

Igualmente, é esperado que esses bancos participem do leilão de privatização do Banespa, que deve ocorrer em 1999. Mas, como a privatização dos bancos públicos é importante via de acesso para os bancos estrangeiros que querem entrar no mercado brasileiro e/ou ampliar a presença, os bancos nacionais vão, certamente, enfrentar competidores importantes. 
Já no mercado de atacado, em particular no segmento de banco de investimento, cada vez mais dominado por bancos globais, os bancos brasileiros vão precisar se associar para não serem expulsos do mercado. Todavia, existe para esses bancos a alternativa de se transformarem em "butiques" especializadas em negócios locais e regionais, que não são atendidos pelos grandes bancos, oferecendo um serviço personalizado para seus clientes (taylormade). Enquanto algumas instituição de atacado escolhem a especialização, outras, como o Bozano Simonsen, apostam na diversificação. Esse banco que adquiriu o Meridional, em um disputado leilão, do qual participou o grande banco de investimento americano Goldman Sachs, pretende ampliar suas atividades no varejo.

A entrada do HSBC e o avanço do Santander devem também implicar um reposicionamento dos bancos estrangeiros já com significativa atuação no País. Porém essas instituições levam vantagens em relação aos novos bancos, os quais enfrentam as dificuldades inerentes ao processo de reordenamento institucional resultante das aquisições e absorções. Em geral, a reorganização é um processo lento, demorado e complexo, pois o choque de culturas é muito forte. Ademais, o relativo desconhecimento dos recém-chegados acerca das peculiaridades da economia e sociedade brasileira constitui um empecilho adicional para um rápido avanço sobre as posições dos rivais, conferindo-lhes o tempo necessário para a revisão das estratégias e construção de novas vantagens competitivas. Exemplos nesse sentido são fornecidos pelos bancos americanos, Citibank e BankBoston, que têm ampliado suas redes de agências.

Pela Tabela 4, que apresenta as alterações no ranking dos dez maiores bancos privados do Brasil por tamanho de ativos (posição em junho de $1994 \mathrm{e}$ em dezembro de 1998), verifica-se que, nesses quatro anos de Plano Real, os grandes bancos varejistas consolidaram sua liderança no sistema, mas houve mudanças significativas nas demais posições. Os bancos Bamerindus e Nacional, que ocupavam lugar de destaque em junho de 1994 (respectivamente, terceiro e quarto lugar), faliram, e tais posições são atualmente ocupadas pelo Unibanco (comprador do Nacional) e pelo ABN Amro que adquiriu o Banco Real. Os bancos estrangeiros também conquistaram maior espaço no sistema nacional. Enquanto em junho de 1994 havia apenas um (o Lloyds) entre os dez maiores bancos do país, em dezembro de 1998 cinco deles ocupavam posições entre os dez maiores.

Nesse contexto de abertura do sistema financeiro ao capital externo, a maior vulnerabilidade dos bancos brasileiros reside no volume de capital, muito reduzido em comparação com os bancos estrangeiros. Como se constata pelo exame da Tabela 1 e 3, o banco inglês HSBC possui sozinho um volume de capital tiers one equivalente a $60,67 \%$ do patrimônio líquido do sistema bancário brasileiro. 
Tabela 4: Ranking dos Bancos Privados, por ativos

\begin{tabular}{|c|c|c|c|c|c|}
\hline \multicolumn{3}{|c|}{ Junho de 1994} & \multicolumn{3}{|c|}{ Dezembro de 1998} \\
\hline Ranking & Banco & Ativos & Ranking & Banco & Ativos \\
\hline $1^{\underline{0}}$ & Bradesco & 19,3 & $1^{-0}$ & Bradesco & 40,85 \\
\hline $2^{\circ}$ & Itaú & 14,4 & $2^{\circ}$ & Itaú & 32,20 \\
\hline $3^{\circ}$ & Bamerindus & 12,0 & $3^{o}$ & Unibanco & 22,58 \\
\hline $4^{9}$ & Nacional & 11,2 & $4^{9}$ & ABN Amro ${ }^{(1)}$ & 20,68 \\
\hline $5^{\circ}$ & Unibanco & 9,6 & $5^{\mathrm{o}}$ & Safra & 12,62 \\
\hline $6^{\circ}$ & Real & 7,6 & $6^{\mathrm{o}}$ & HSBC Bamerindus & 11,45 \\
\hline $7^{\circ}$ & Safra & 6,5 & $7^{\circ}$ & Sudameris $^{(2)}$ & 9,63 \\
\hline $8^{\mathrm{o}}$ & $\mathrm{BCN}$ & 6 & $8^{\circ}$ & Santander ${ }^{(3)}$ & 9,27 \\
\hline $9^{0}$ & Lloyds & 5,4 & $9^{0}$ & Bozano Simonsen $^{(4)}$ & 8,27 \\
\hline $10^{\circ}$ & Econômico & 5,1 & $10^{\circ}$ & Bank Boston & 7,77 \\
\hline
\end{tabular}

Fonte: Balanços Patrimoniais dos Bancos

Notas:

(1) Consolidado ABN Amro Bank e Banco Real

(2) Consolidado Sudameris e América do Sul

(3) Consolidado, inclui o Noroeste

(4) Consolidado, inclui o Meridional

\section{Tendências e perspectivas}

O sistema financeiro brasileiro apresenta um forte potencial de crescimento tanto no que se refere à intermediação financeira tradicional, dado que os bancos que operam no mercado de crédito partem de uma situação de baixa alavancagem, quanto na oferta de serviços bancários, tais como administração de portfólio, custódia e emissão de títulos e custódia de ações etc. Nesse quadro, a participação estrangeira no sistema financeiro também deverá continuar aumentando, em virtude do potencial de crescimento e lucratividade que o sistema financeiro doméstico oferece mesmo num contexto como o atual de incerteza quanto ao comportamento do câmbio, dos juros e dos preços.

$O$ processo de reestruturação do sistema financeiro associado à abertura ao capital externo está longe do seu término. O movimento em curso não permite interpretações definitivas, ao contrário, suscita inúmeras questões sobre a configuração do sistema financeiro nacional, a melhoria na qualidade dos serviços bancários, a definição de um padrão de financiamento para a economia brasileira, com o necessário alongamento dos prazos das aplicações financeiras e das operações de crédito.

Ao contrário do que advogam certos defensores da abertura do sistema financeiro às instituições estrangeiras (por exemplo Barros \& Almeida (1997), não existe, porém, nenhuma garantia prévia de que a entrada de novos competidores refletirá na diminuição das tarifas e dos custos dos empréstimos, nem na melhoria da qualidade dos serviços bancários prestados à população. É possível que as 
grandes empresas e os segmentos de renda elevada se beneficiem, na medida em que têm condições de negociar tarifas, comissões e exigir tratamento diferenciado. Mas a grande maioria que não demanda produtos financeiros mais sofisticados dificilmente conseguirá escapar das longas filas e das altas tarifas. Mesmo porque não é possível mudar de banco com a mesma facilidade com que se troca de marca de produtos de consumo. Ademais a concorrência via preços é apenas uma dentre várias das estratégias competitivas que uma instituição bancária pode adotar. ${ }^{11}$

$\mathrm{Na}$ atividade bancária e financeira, a diferenciação em relação aos rivais é um importante mecanismo estratégico. Os bancos procuram se singularizar, diferenciando-se uns dos outros, pela construção de uma imagem de experiência, de tradição e de solidez, pela utilização agressiva de técnicas de marketing, pela qualidade de suas equipes operacionais, pelas informações 'privilegiadas' obtidas nos relacionamentos estritos e contínuos com suas clientelas, pelo desenvolvimento de novos instrumentos e práticas financeiras que correspondem às necessidades de seus clientes etc. Todos esses meios possibilitam a obtenção de vantagens do tipo monopolista e, em conseqüência, maiores lucros.

A incorporação de inovações tecnológicas é também uma arma importante utilizada pelos bancos em busca de vantagens competitivas. A tecnologia desempenha um papel relevante, tanto para a redução dos custos, como para a ampliação das receitas. Os domínios de aplicação da telemática nas atividades bancárias e financeiras são vastos, destacando-se: a análise financeira; o acompanhamento dos riscos; o tratamento e a oferta de informações; a gestão de portfólios de ações, de títulos e de participações; e o gerenciamento de tesouraria em divisas. Porém tais desenvolvimentos viabilizaram a emergência de novos competidores em atividades anteriormente dominadas pelos bancos. Por essa razão, os investimentos em informática são importantes fontes de vantagens competitivas, tanto para os bancos individualmente, como para seus concorrentes diretos.

Os defensores da abertura do sistema financeiro ao capital estrangeiro exageram, em geral, na ênfase dos aspectos positivos da maior presença estrangeira no País. Há, todavia, um argumento que se destaca pela sua consistência. De fato, a entrada e a ampliação da participação do capital estrangeiro aumenta a solidez patrimonial do sistema bancário brasileiro. Instituições mais fortes têm maior capacidade de absorção dos choques macroeconômicos, reduzindo, assim, a possibilidade de crise sistêmica.

Porém a possibilidade de uma migração de recursos para os bancos estrangeiros - em decorrência de uma fuga para a segurança por parte do público, caso se verifique a ameaça de insolvência de algum grande banco privado nacional teria, sem dúvida, efeitos perversos para a gestão macroeconômica. Num quadro

${ }^{11}$ Para maiores detalhes sobre os mecanismos de concorrência bancária, ver Freitas (1997b). 
de predomínio de instituições financeiras estrangeiras, a autoridade monetária enfrentaria uma maior dificuldade em manejar as condições de liquidez do sistema, se uma situação semelhante a de 1995 se reproduzisse. Nessa ocasião, a preferência por liquidez dos bancos inviabilizou os esforços do Banco Central com vistas a reativar o mercado interbancário. Sem o concurso do Banco do Brasil e Caixa Econômica Federal, os quais desempenharam um papel de emprestadores de última instância para os bancos em dificuldade, sobretudo, para o Banco Nacional e o Bamerindus, a fragilidade financeira do sistema bancário poderia ter se agravado, desdobrando-se em uma crise bancária generalizada.

Ademais, sem uma profunda reformulação na política macroeconômica, e em particular sem a definição de uma política financeira que priorize o longo prazo, não surgirão mecanismos para o financiamento do desenvolvimento. No Brasil, onde já estavam presentes importantes bancos estrangeiros de distintas procedências, o sistema financeiro privado jamais se envolveu na concessão de financiamento de longo prazo para as empresas produtivas, exceto como repassadores de capital de empréstimo externo ou de recursos das agências oficiais de fomento. A entrada de novas instituições financeiras estrangeiras não vai promover por si só a resolução desse problema.

Os bancos como todos os outros agentes econômicos possuem preferência pela liquidez e expectativas em relação ao futuro, que norteiam as estratégias traçadas em suas buscas incessantes de valorização. Como o desejo dos bancos em se manterem líquidos depende de suas considerações otimistas ou pessimistas sobre o estado dos negócios ao longo do ciclo econômico, é possível que, em certas circunstâncias, eles decidam racionar o crédito, refreando o crescimento econômico ou mesmo conduzindo à regressão da produção e dos investimentos. Como foi visto recentemente no País, no episódio da desvalorização do Real, quando obtiveram lucros espetaculares, os bancos podem igualmente decidir privilegiar o financiamento da circulação financeira, seja concedendo crédito aos agentes especuladores ou realizando atividades especulativas com seus recursos próprios. ${ }^{12}$

A instabilidade, a incerteza quanto ao rumo da economia e a política de juros elevados constitui um desestímulo a retomada dos investimentos e do crescimento. A persistir esse quadro, será difícil que o tão esperado financiamento de longo prazo se torne realidade.

A política de abertura externa mediante utilização do Artigo 52 das Disposições Constitucionais Transitórias está na prática promovendo uma reforma ad hoc do sistema financeiro nacional. É sabido que as finanças e as ações dos agentes econômicos não são neutras em seus efeitos para o desenvolvi-

12 De acordo com dados divulgados pela Gazeta Mercantil, a desvalorização do Real proporcionou ao sistema bancário brasileiro, e em particular, aos bancos estrangeiros, lucros no mês de janeiro várias vezes superiores aos obtidos ao longo do ano de 1998. (Carvalho, 1999:B1). 
mento social e econômico das nações. Por essa razão, uma reforma da institucionalidade monetária e financeira do País precisaria ser amplamente discutida com a sociedade ou com seus representantes e não ficar na dependência do poder discricionário de poucas pessoas. A entrada estrangeira é um tema tão controverso, que encontra opositores e defensores em ambos extremos do espectro ideológico. Razão a mais para que seja objeto de decisão, a partir de um debate político franco e democrático.

Desde outubro de 1988, o Artigo 192 está à espera de regulamentação. As discussões sobre esse tema tiveram início em 1991 quando foi criada a Comissão Especial - Sistema Financeiro Nacional da Câmara dos Deputados. Inúmeros anteprojetos já foram apresentados e debatidos nessa Comissão, sem que fossem, contudo, levados à discussão e aprovação em plenário. Vários fatores explicam o grande desinteresse pela regulamentação do referido Artigo. Do lado do governo, isso se explica pelo fato que a lei 4.595 , em vigor até a elaboração da nova lei complementar, confere ampla liberdade e poderes de atuação e de intervenção à autoridade monetária. Do lado dos banqueiros brasileiros, havia, até a aprovação pelo presidente da Exposição de Motivo $\mathrm{n}^{\circ} 311$ em 1995, o conforto de estarem livre da ameaça da entrada de novos rivais estrangeiros, ou mesmo da ampliação da participação dos estrangeiros já em atividade. Talvez com a freqüente utilização pelo governo do Artigo 52 das Disposições Constitucionais Transitórias, o Congresso Nacional finalmente se interesse em regulamentar o artigo 192 e dar um ordenamento ao sistema financeiro nacional.

\section{Referências bibliográficas}

BANKER (The) (1999) “Top 50 global banks". The Banker, London: Financial Times Magazines, February, pp. 40-41.

(1998) “Top 1000 world banks". The Banker, London: Financial Times Magazines, July.

BARROS, José Roberto Mendonça \& ALMEIDA Jr., M. F. (1997) Análise do ajuste do sistema financeiro no Brasil. Brasília, D.F.: Ministério da Fazenda, mimeo, abril.

BLOMMESTEIN, H. J. (1995) "Structural changes in financial markets: overview of trends and prospects" in: The financial landscape: forces shaping the revolution in banking, risk management and capital markets. Paris: OECD, pp. 9-47.

BORGES, Cristina \& LUANE, Kátia (1997) Patrimônio negativo apressou negociações. Gazeta Mercantil, São Paulo, 4 de set., p. A-1 e B-3.

CARVALHO, M. Cristina de (1999) "Bancos lucram em janeiro além do esperado". Gazeta Mercantil, São Paulo, 3 de março, pp. B-1.

(1997) "Ainda longe do padrão internacional de eficiência", Gazeta Mercantil, São Paulo, 28 de julho, pp. B-18.

CINTRA, Marcos Antonio Macedo (1997) As transformações na estrutura do sistema financeiro dos Estados Unidos: a montagem de um novo regime monetário-financeiro 
(1980-1995). Campinas: IE/Unicamp (tese de doutoramento).

ECONOMIST (The) (1998) "Europe's lovesick bankers". The Economist, London, January, $10^{\text {th }}$, pp. 61-62.

FREITAS, Mª Cristina Penido (1997a) "Política financeira e fragilidade bancária". São Paulo: Fundap/Instituto de Economia do Setor Público, outubro, mimeo. (1997b) Concurrence bancaire, spéculation et instabilité financière: une lecture hétérodoxe de l'évolution récente du système financier international. Villetaneuse: Université de Paris XIII/U.F.R. de Sciences Economiques et Gestion (Tese de Doutoramento). (1989) Bancos brasileiros no exterior: expansão, crise e ajustamento. Campinas: Unicamp/Instituto de Economia (Dissertação de Mestrado).

MEDEIROS, Ricardo (1998) "País terá mais três bancos estrangeiros." Gazeta Mercantil, São Paulo, 20-22 de fevereiro, pp. B-2.

OECD (1992) Nouveaux défis pour les banques. Paris: OECD. 